Research Article

\title{
Investigation on Mechanical Properties and Reaction Characteristics of Al-PTFE Composites with Different Al Particle Size
}

\author{
Jia-xiang Wu $\left(\mathbb{D}\right.$, Xiang Fang $\left(\mathbb{D}\right.$, Zhen-ru Gao $\mathbb{D}^{D}$, Huai-xi Wang $(\mathbb{D}$, Jun-yi Huang $(\mathbb{D}$, \\ Shuang-zhang $W u(\mathbb{D}$, and Yu-chun $L i$ \\ College of Field Engineering, PLA Army Engineering University, Hou Biaoying Road No. 88, Nanjing, Jiangsu 210007, China \\ Correspondence should be addressed to Yu-chun Li; liyuchunmail@sina.com
}

Received 4 December 2017; Revised 24 January 2018; Accepted 4 February 2018; Published 14 March 2018

Academic Editor: Zhiping Luo

Copyright ( 2018 Jia-xiang Wu et al. This is an open access article distributed under the Creative Commons Attribution License, which permits unrestricted use, distribution, and reproduction in any medium, provided the original work is properly cited.

\begin{abstract}
Al-PTFE (aluminum-polytetrafluoroethylene) serves as one among the most promising reactive materials (RMs). In this work, six types of Al-PTFE composites with different Al particle sizes (i.e., $50 \mathrm{~nm}, 1 \sim 2 \mu \mathrm{m}, 6 \sim 7 \mu \mathrm{m}, 12 \sim 14 \mu \mathrm{m}, 22 \sim 24 \mu \mathrm{m}$, and $32 \sim 34 \mu \mathrm{m}$ ) were prepared, and quasistatic compression and drop weight tests were conducted to characterize the mechanical properties and reaction characteristics of Al-PTFE composites. The reaction phenomenon and stress-strain curves were recorded by a high-speed camera and universal testing machine. The microstructure of selected specimens was anatomized through adopting a scanning electron microscope (SEM) to correlate the mesoscale structural characteristics to their macroproperties. As the results indicated, in the case of quasistatic compression, the strength of the composites was decreased (the yield strength falling from $22.7 \mathrm{MPa}$ to 13.6 $\mathrm{MPa}$ and the hardening modulus declining from $33.3 \mathrm{MPa}$ to $25 \mathrm{MPa}$ ) with the increase of the Al particle size. The toughness rose firstly and subsequently decreased and peaked as $116.42 \mathrm{MJ} / \mathrm{m}^{3}$ at $6 \sim 7 \mu \mathrm{m}$. The reaction phenomenon occurred only in composites with the $\mathrm{Al}$ particle size less than $10 \mu \mathrm{m}$. In drop weight tests, six types of specimens were overall reacted. As the $\mathrm{Al}$ particle size rose, the ignition energy of the composites enhanced and the composites turned out to be more insensitive to reaction. In a lower strain rate range $\left(10^{-2} \cdot \mathrm{s}^{-1} \sim 10^{2} \cdot \mathrm{s}^{-1}\right)$, Al-PTFE specimens take on different mechanical properties and reaction characteristics in the case of different strain rates. The formation of circumferential open cracks is deemed as a prerequisite for Al-PTFE specimens to go through a reaction.
\end{abstract}

\section{Introduction}

Reactive materials (RMs), comprised of two or more nonexplosive solid components and also known as impactinitiated energetic material, have aroused great attentions in recent years. Polytetrafluoroethylene filled by aluminum particles (Al-PTFE) is one of the most promising RMs and has been studied extensively, owing to its easiness to deform and higher strength, stability, and energy density compared with traditional explosive [1-3]. When Al-PTFE is subjected to sufficiently strong mechanical stimulus, violent chemical reaction will occur with new substance produced and large amount of heat released. In this regard, Al-PTFE takes on numerous prominent applications in military applications.
For instance, it can be made into the warhead shell functionalized to cause secondary damage to evidently increase the damage effect. Furthermore, it can also be adopted in the systems of air defense, antimissile, obstacle breaking, and rocket propulsion [4].

Al-PTFE pertains to both composite materials and energetic materials; thus, this paper firstly focuses on researching the mechanical properties taken on by materials, describing the deformation, yield, and failure processes of materials in the case of different strain rates to determine the constitutive relation, fracture characteristics, and fatigue resistance in different applications [5-8]. Secondly, this paper shall anatomize the reaction characteristics of materials, calculate the antioverload capacity, reaction threshold, 
impact sensitivity, and energy release rate through characterizing the reaction process, and establish a reaction mechanism model [9-11].

Currently, the experimental researches performed worldwide primarily focus on the engineering strain of Al-PTFE in the case of different influence factors, and the performance shall be varied with the addition of different fillers. Zheng et al. [12] studied the shock initiation process of nano-Al-PTFE with time- and wavelength-resolved emission spectroscopy. The results showed that the reaction was associated with the arrival of the compressive release wave and shear release waves from the flyer plate edges. Eventually, a mechanism was proposed in which tensile stresses resulting from compressive and shear waves cause the $\mathrm{Al}$ shells to crack open, consequently allowing hot PTFE to react with Al. Feng et al. $[13,14]$ discovered that Al-PTFE mixtures through special heat treatment could go through severe reaction under quasistatic compression. The influence of sintering temperature and equivalence ratio on reaction of Al-PTFE was ascertained. On that basis, a crack-induced initiation mechanism was put forward. Ge et al. [15] prepared three kinds of PTFE-Al-W samples with different component mass ratios which were fabricated under a much lower sintering temperature and for a much shorter duration. They evaluated the mechanical and impact-induced initiation characteristics of the brittle PTFE-Al-W materials through carrying out quasistatic compression tests, dynamic compression tests, and drop weight tests at room and elevated temperatures. Wang et al. [16] obtained the compress stress-strain curves for a pressed and sintered PTFE-Al-Ni mixtures under uniaxial loading at strain rates ranging from $10^{-2}$ to $3 \times 10^{3} \cdot \mathrm{s}^{-1}$ using an electrohydraulic press and SHPB system. The data measured were adapted to the Johnson-Cook model and showed that this kind of material took on evident strain hardening and strain rate hardening. Herbold et al. [17] studied the impact exerted by the particle size on strength, failure, and shock behavior in PTFE-Al-W granular composites. The result revealed that dynamic mechanical properties of high-density PTFE-Al-W mixtures could be tailored by changing the particle size and the mixture porosity. The reason for this phenomenon was that the force chains between fine metallic particles were formed under dynamic loading.

As the foregoing information indicates, the slight differences of raw material exert different effects on the mechanical properties and reaction characteristics of Al-PTFE as composite materials. For the $\mathrm{Al}$ particle size serving as the basic characteristic, the effect of the $\mathrm{Al}$ particle size on the mechanical properties and reaction characteristics of Al-PTFE materials under quasistatic compression condition are needed to be considered when assessing the safety of the Al-PTFE materials. Besides, it is also extremely significant to study the impact sensitivity of materials, considering materials are vulnerable to impact in the process of production, machining, transportation, and storage. In this paper, six types of Al-PTFE specimens with different $\mathrm{Al}$ particle sizes were prepared, and their mechanical properties and reaction characteristics under quasistatic compression and dynamic impact were investigated. And the failure and ignition mechanism were analyzed associated with the reaction phenomena.

\section{Experimental Setup}

2.1. Specimen Preparation. The initial powders adopted to fabricate samples have the following average size: PTFE: $25 \mu \mathrm{m}$ (purity $>99.0 \%$, from $3 \mathrm{M}$, Shanghai) and Al: $50 \mathrm{~nm}, 1 \sim 2 \mu \mathrm{m}$, $6 \sim 7 \mu \mathrm{m}, 12 \sim 14 \mu \mathrm{m}, 22 \sim 24 \mu \mathrm{m}$, and $32 \sim 34 \mu \mathrm{m}$ (purity $>99.0 \%$, from JT, Hunan). In this study, six types of Al-PTFE specimens which graded from \#1 to \#6, respectively, in accordance with the order of the $\mathrm{Al}$ particle size from small to large were fabricated. And the mass fraction of $\mathrm{Al}$ and PTFE was proportional to the chemical equilibrium ratio $(26 \% / 74 \%)$ to ensure the complete reaction of the material.

The preparation process of specimens involved mixing, cold isostatic pressing, and vacuum sintering on the basis of the patent of Nielson's [18]. Procedure was described as follows: the Al-PTFE mixture was stirred by a motor-driven blender for $20 \mathrm{~min}$ in an ethanol solution, then put into a vacuum drying oven for $48 \mathrm{~h}$ at $60^{\circ} \mathrm{C}$, and cold pressed into cylinders with sizes of $\Phi 10 \mathrm{~mm} \times 10 \mathrm{~mm}$ for the quasistatic compression test and $\Phi 10 \mathrm{~mm} \times 3 \mathrm{~mm}$ for the drop weight test under a compressive pressure of $300 \mathrm{MPa}$. Lastly, the pressed specimens were heated in a vacuum oven at the sintering temperature of $360^{\circ} \mathrm{C}$ for $5 \mathrm{~h}$ in the cases of the heating rate of $90^{\circ} \mathrm{C} \cdot \mathrm{h}^{-1}$ and the cooling rate of $50^{\circ} \mathrm{C} \cdot \mathrm{h}^{-1}$. The temperature history of the sintering cycle is depicted in Figure 1.

2.2. Experimental Procedures. Quasistatic compression tests of the six types of specimens were conducted by using a CMT5105 electrohydraulic press with a maximum loading capacity of $100 \mathrm{kN}$ at $26^{\circ} \mathrm{C}$ of the ambient temperature. The load was applied at the speed of $6 \mathrm{~mm} \cdot \mathrm{min}^{-1}$ corresponding to the nominal strain rate of $0.01 \mathrm{~s}^{-1}$. Prior to tests, all contact surfaces of the specimens were lubricated with petroleum jelly to alleviate the effect of friction. Triplicate experiments were carried out for each type of specimens. In total, eighteen specimens-three for each of the six types of specimens-were tested to ensure the reliability of obtained results.

A fall hammer impact sensitivity test was performed to investigate the sensitivity and impact-initiation characteristics of Al-PTFE materials in the ambient temperature of $26^{\circ} \mathrm{C}$. The instrument has a drop mass of $10 \mathrm{~kg}$ which can be released from a maximum height of $156 \mathrm{~cm}$, so the maximum strain rate of nearly $500 \mathrm{~s}^{-1}$ and the maximum output energy of $152.9 \mathrm{~J}$ can be achieved. The specimens were placed on the anvil of the tester without constraint and impacted directly by the drop hammer falling free. The impact sensitivities of the six types of materials were calculated by the characteristic drop height $\left(H_{50}\right)$, at which Al-PTFE specimens can react with a $50 \%$ possibility. To observe the impact process more accurately, time sequences of the drop weight tests were recorded by a high-speed camera with the frame rate up to 20,000 frames/s.

To investigate the relation between the microstructure of the materials and the reaction mechanisms, Hitachi S-3400N II scanning electron microscope (SEM) was used to observe the interior microstructures of the materials. 


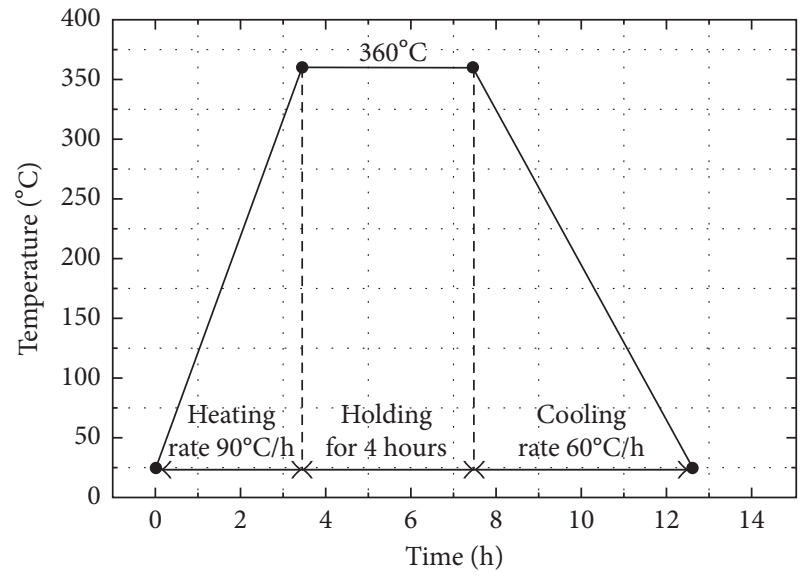

Figure 1: The temperature history of the sintering cycle.

\section{Results and Discussion}

3.1. Mechanical Properties under Quasistatic Compression. Figure 2 shows the true stress-strain curves obtained by triplicate experiments of specimen \#2 before sintering and after sintering. It can be found that specimen \#2 after sintering had much higher strength than that of before sintering. The difference of the strength was mainly attributed to the recrystallization of PTFE, which can be confirmed from the scanning electron microscope (SEM) photographs in Figures 3(a) and 3(b). As can be seen from Figures 3(a) and 3(b), before sintering, many of voids and pores existed between Al particles and PTFE. After sintering, due to the recrystallization of PTFE, Al particles were embedded in the PTFE matrix very tightly without voids, resulting in which the strength of the specimen was enhanced greatly. Besides, it can be observed that the curves take on a high degree of agreement, meaning that the experimental results are in good consistency.

The true stress-strain curves of the six types of Al-PTFE specimens under quasistatic compression are shown in Figure 4 . The overall shape of the compressive stress-strain curves of the materials is greatly affected by the Al particle size, and the effect is primarily reflected in the strain hardening stage. The mechanical property parameters of the six types of specimens calculated based on the stress-strain data are presented in Table 1 , and it can be found that the yield strength and strain hardening modulus which represent the strength of Al-PTFE materials decreased as the Al particle size rose. When the $\mathrm{Al}$ particle size increased from $0.05 \mu \mathrm{m}$ to $32 \mu \mathrm{m}$, the yield strength of Al-PTFE specimens decreased from $22.7 \mathrm{MPa}$ to $13.6 \mathrm{MPa}$, and the strain hardening modulus (the slope of the tangent line of the strain hardening region of the stress-strain curve) decreased from $33.3 \mathrm{MPa}$ to $25.0 \mathrm{MPa}$. The toughness indicates the energy absorbed by the unit volume before the failure, which characterizes the ability to resist fracture of the specimens. Table 1 presents that the toughness (the area under the stress-strain curve) firstly increased and decreased subsequently, reaching the maximum of $116.42 \mathrm{MJ} / \mathrm{m}^{3}$ at $6 \sim 7 \mu \mathrm{m}$.

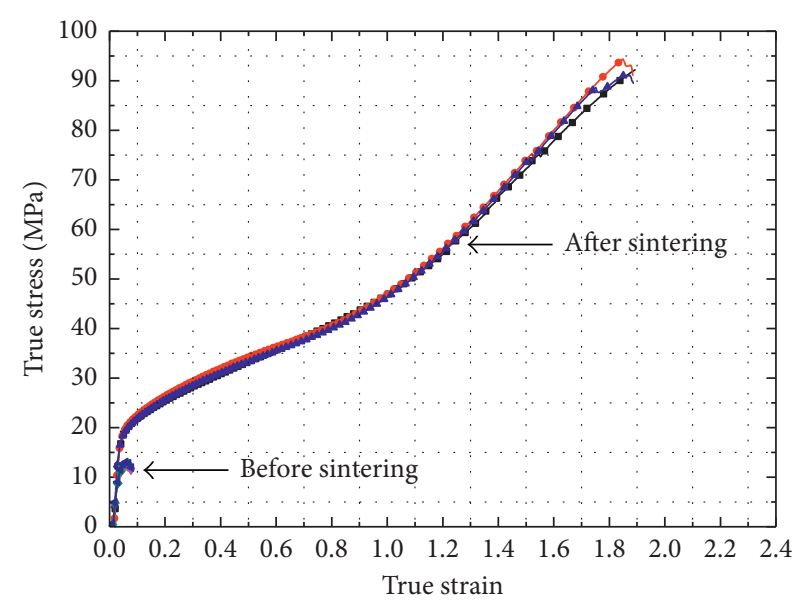

FIgURE 2: True stress-strain curves of specimen \#2 before sintering and after sintering.

To anatomize the effect of the $\mathrm{Al}$ particle size on microstructure of the Al-PTFE specimen, the sintered specimens were photographed by SEM, and Figures 3(b) and 3(d) compare the internal microstructures of specimens \#2, \#1, and \#4. As can be seen, the distribution of $\mathrm{Al}$ particles of $50 \mathrm{~nm}$ in the PTFE matrix was best uniform in all of specimens; this uneven distribution resulted in specimen \#4 tending to form the stress concentration; thus, specimen \#4 was more prone to local deformation and even failure compared with specimens \#1 and \#2. In the perspective of fracture mechanics, separation of metal particles from the matrix and the fracture of matrix were two major mesoscale mechanisms for failure [19]. Metal particles with a smaller size were more difficult to peel off from the matrix because particles were bonded to the matrix more tightly and the gaps between each other were smaller (Figure 3(c)); consequently, specimen\#1 was more difficult to be damaged when compressed and presented a higher strength. Herbold et al. [17] found that metal particles could form force chains that can transmit and bear the stress when the material was compressed. The characteristics of the force chains had a significant influence on the macroscopic response behavior of the specimen. During compression, the force chains went through three processes of generation, destruction, and regeneration. The smaller the particle size, the stronger the regeneration ability of the force chains was, and therefore, the strength of specimen \#1 was highest.

\subsection{Reaction Characteristics under Quasistatic Compression.} Quasistatic compression tests were carried out for six types of Al-PTFE specimens. It can be observed that violent reaction happened to specimens \#1, \#2, and \#3, while no reaction occurred in specimens \#4, \#5 and \#6. The reaction phase of specimens \#1, \#2, and \#3 recorded by high-speed camera are shown in Figure 5. As can be seen, the reaction of specimen \#1 was the most violent, and the ignition phenomenon was the most evident. By comparison, the reaction intensity of specimen \#3 was far less than that of specimens $\# 1$ and \#2, and the ignition was comparatively weaker. 


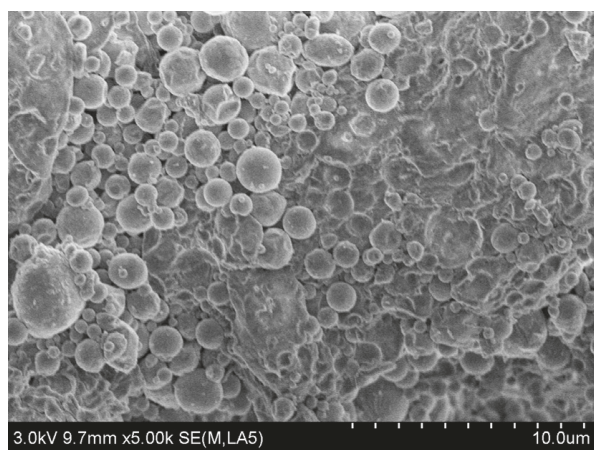

(a)

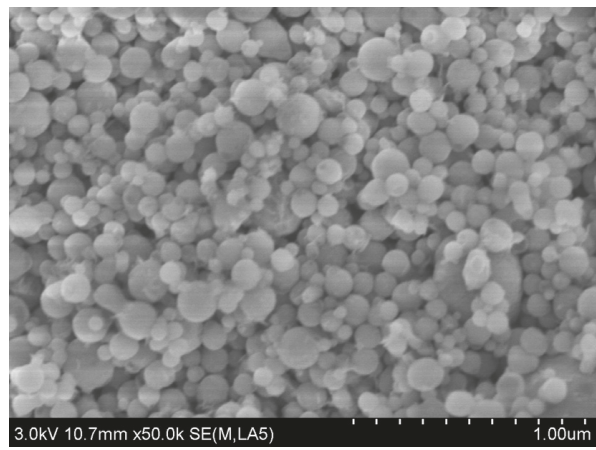

(c)

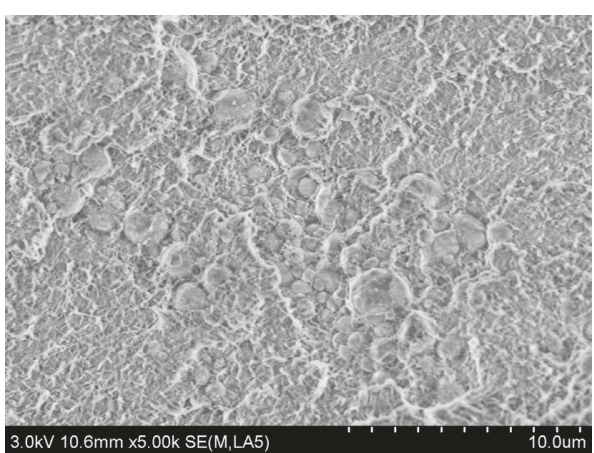

(b)

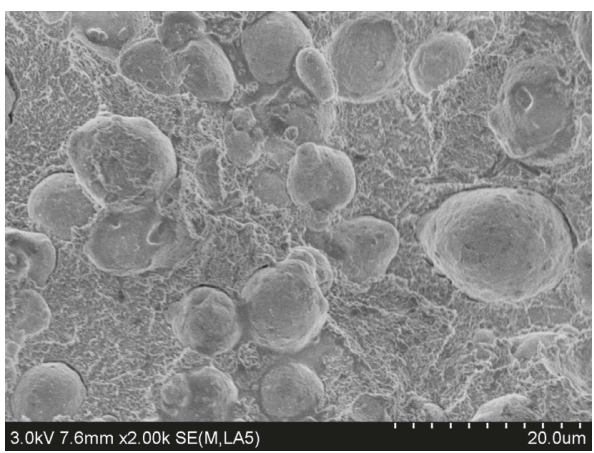

(d)

Figure 3: The internal microstructures of specimens. (a) Specimen \#2 before sintering. (b) Specimen \#2 after sintering. (c) Specimen \#1 after sintering. (d) Specimen \#4 after sintering.

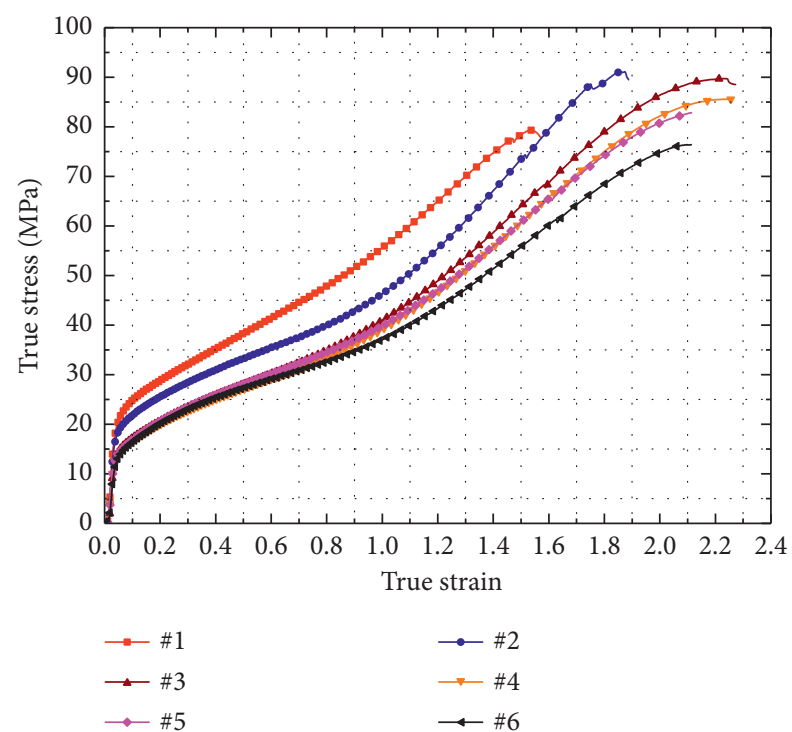

FIgURE 4: True stress-strain curves of specimens \#1-\#6.

Figure 6 presents the state of six types of Al-PTFE specimens after quasistatic compression. It can be found that specimen \#1 reacted completely while specimens \#2 and \#3 reacted partly, and the reaction was initiated by the circumferential open crack which propagated outward from the radial direction. The black solid residuals can be judged as $\mathrm{C}$ (carbon black) based on the following reaction equation:

$$
4 \mathrm{Al}+3\left(-\mathrm{C}_{2} \mathrm{~F}_{4}-\right) \rightarrow 4 \mathrm{AlF}_{3}+6 \mathrm{C}
$$

On the contrary, specimens \#4, \#5, and \#6 failed arising from the formation of internal developed crack, and no circumferential open crack was observed. In accordance with the frame rate and the number of photos captured by the high-speed camera, the duration of the reaction can be approximately calculated through defining the first observation of the ignition phenomenon as the $t=0$ moment. Table 2 illustrates the reaction duration of specimens \#1, \#2, and \#3 under quasistatic compression. As can be seen from Table 2, the reaction duration of specimen \#1 was the shortest (100 150 ms), and the reaction duration of specimen \#3 was the longest (1400 1800 ms). The conclusion can be reached that the reaction speed of Al-PTFE specimens takes on a downward trend with the increase of the $\mathrm{Al}$ particle size.

The foregoing phenomena can be explicated as follows. For one thing, the specific surface area of particles decreases with the increase of the particle size, that is, surface effect [20]. The Al particles in specimen \#1 have the largest specific surface area compared with the others (Table 2), and the contact area between particles is the largest among those under the identical mass condition, thereby enlarging the friction area between the particles and releasing more heat in the process of quasistatic compression, which impel specimen \# 1 to react more easily and rapidly. For another, during studying the effect of the $\mathrm{Al}$ particle size on the thermal degradation of Al-PTFE mixtures, Osborne and Pantoya [21] 
TABLE 1: Mechanical properties of specimens \#1-\#6 under quasistatic compression.

\begin{tabular}{|c|c|c|c|c|c|c|}
\hline Number & $\begin{array}{l}\text { Al particle size } \\
(\mu \mathrm{m})\end{array}$ & $\begin{array}{l}\text { Elastic modulus } \\
(\mathrm{MPa})\end{array}$ & $\begin{array}{l}\text { Yield strength } \\
(\mathrm{MPa})\end{array}$ & $\begin{array}{l}\text { Hardening modulus } \\
(\mathrm{MPa})\end{array}$ & $\begin{array}{l}\text { Failure stress } \\
(\mathrm{MPa})\end{array}$ & $\begin{array}{c}\text { Toughness } \\
\left(\mathrm{MJ} / \mathrm{m}^{3}\right)\end{array}$ \\
\hline 1 & 0.05 & 410.6 & 22.7 & 33.3 & 79.3 & 74.37 \\
\hline 2 & $1 \sim 2$ & 400.7 & 19.8 & 29.5 & 92.8 & 106.38 \\
\hline 3 & $6 \sim 7$ & 352.6 & 14.8 & 26.4 & 89.7 & 116.42 \\
\hline 4 & $12 \sim 14$ & 344.9 & 14.1 & 25.3 & 85.6 & 108.98 \\
\hline 5 & $22 \sim 24$ & 340.2 & 14.3 & 25.2 & 82.9 & 97.18 \\
\hline 6 & $32 \sim 34$ & 322.4 & 13.6 & 25.0 & 76.4 & 90.47 \\
\hline
\end{tabular}
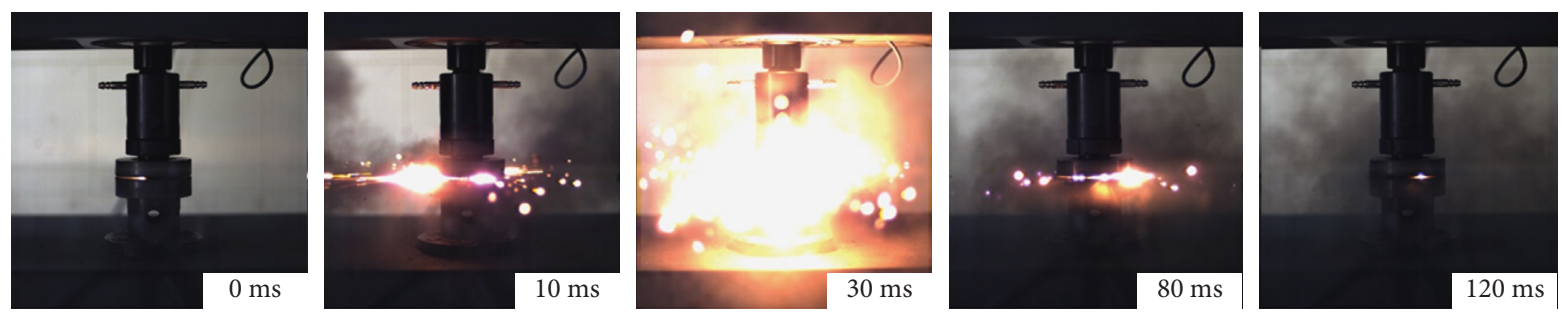

(a)
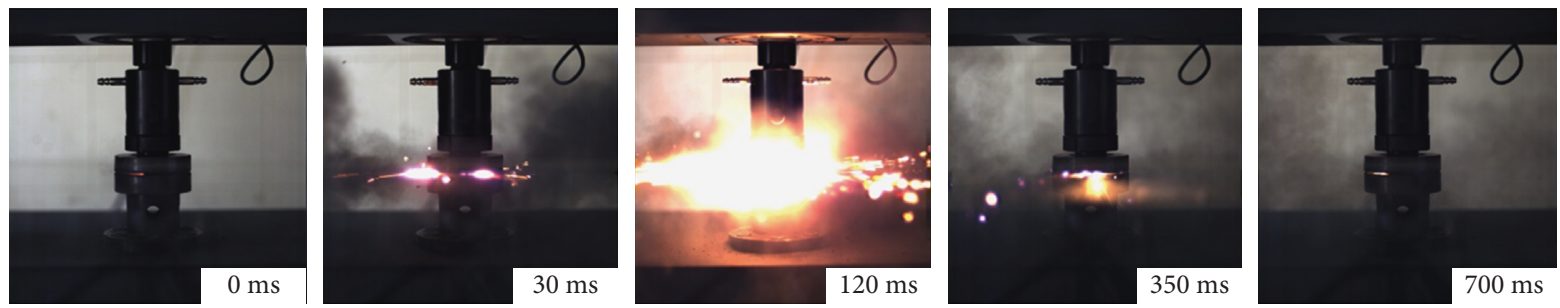

(b)
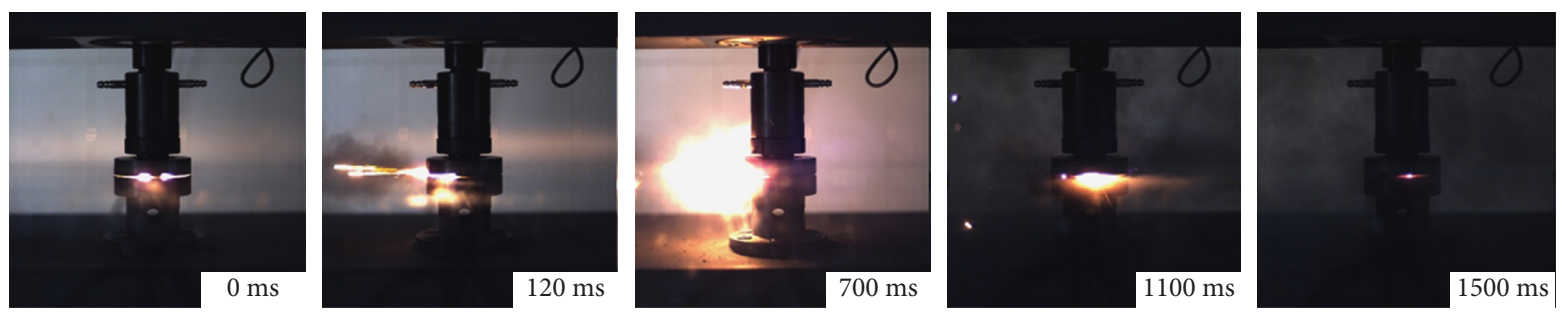

(c)

FIGURE 5: Reaction phase of specimens \#1, \#2, and \#3 under quasistatic compression. (a) Specimen \#1. (b) Specimen \#2. (c) Specimen \#3.

found that nano-Al-PTFE mixtures had obvious preignition reaction (PIR) phenomenon when heated over $400^{\circ} \mathrm{C}$, which contributes to accelerating the reaction of Al-PTFE.

Through comparing the change of mechanical properties of different specimens and analyzing the reaction phenomena in the quasistatic compression test, the following conclusions can be drawn. On the one hand, for the specimen \#1 which can react under quasistatic compression, it was easier to form circumferential open crack by virtue of its highest strength though it took on the worst toughness. The local hot spots were generated at the tip of the crack to trigger the specimen reaction. There was a similar case for specimens \#2 and \#3 in which activation reaction showed up as circumferential open crack was formed. On the other hand, for the specimens \#4, \#5, and \#6 not capable of reacting under quasistatic compression, although they took on toughness outstripping that of specimen $\# 1$, the internal developed crack appeared in the specimen before the absorbed energy was inadequate to trigger the materials by virtue of their low strength. And the crack could not generate the local hot spots of the activation reaction, so the specimen failed to react.

3.3. Reaction Characteristics under Drop Weight Test. The impact sensitivities of the six types of Al-PTFE specimens were calculated by the characteristic drop height $\left(H_{50}\right)$, at which the specimen can react with a $50 \%$ possibility. The experimental procedure by which the $50 \%$ point is obtained is an application of the well-known "up-anddown technique" [22]. In this study, fifteen specimens for each of the types of materials were tested, and the experimental data are recorded in Figure 7 based on "up-anddown technique." 

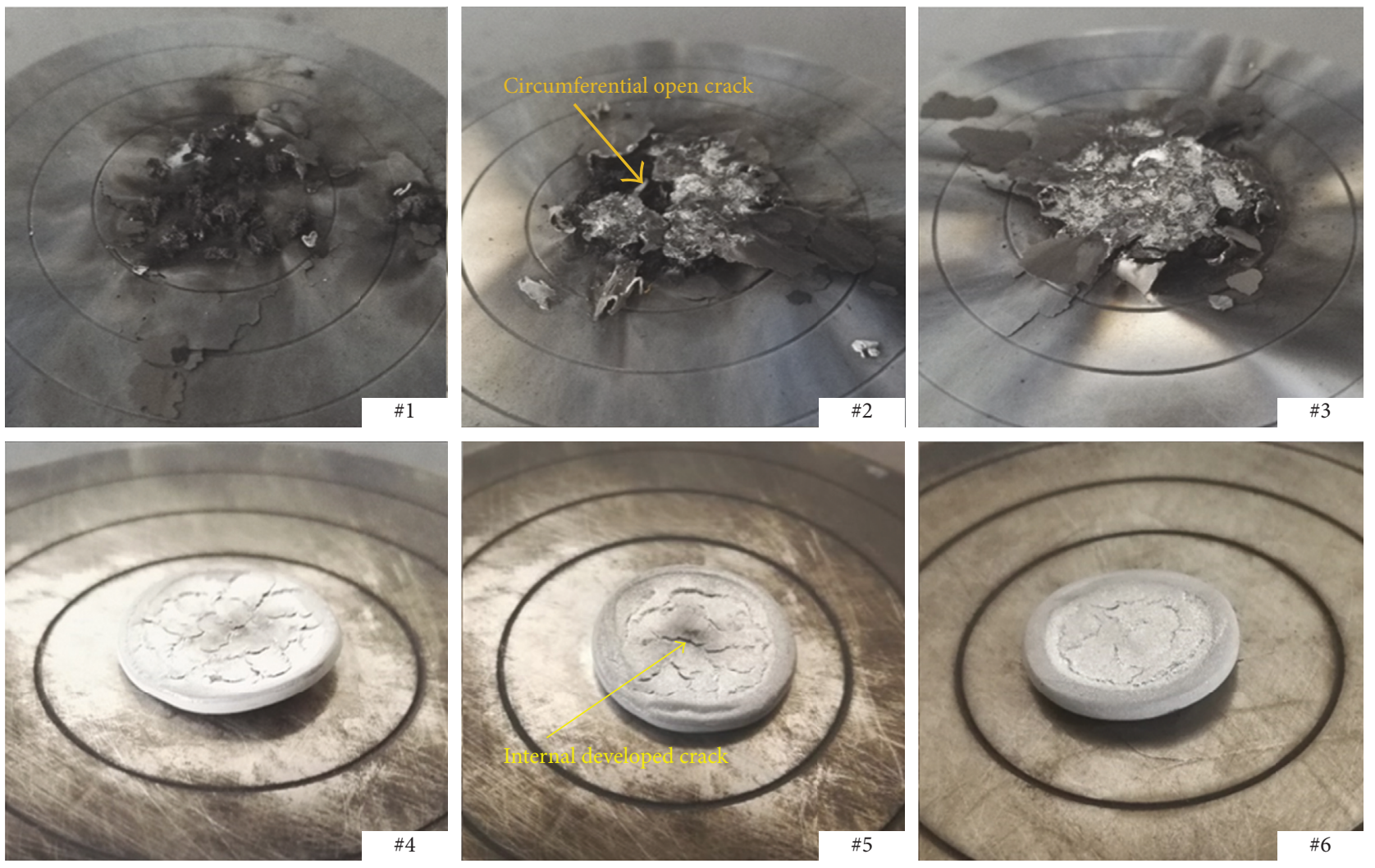

Figure 6: The states of specimens \#1-\#6 after quasistatic compression.

TABLE 2: The reaction duration and specific surface area of specimens \#1-\#6.

\begin{tabular}{lcc}
\hline Number & Reaction duration $(\mathrm{ms})$ & Specific surface area $\left(\mathrm{m}^{2} / \mathrm{g}\right)$ \\
\hline 1 & $100 \sim 150$ & 44.44 \\
2 & $600 \sim 800$ & 2.22 \\
3 & $1400 \sim 1800$ & 0.37 \\
4 & - & 0.19 \\
5 & - & 0.10 \\
6 & - & 0.07 \\
\hline
\end{tabular}

Because the absorbed energy of the specimen is similar to the potential energy of the drop mass, the characteristic drop height $\left(H_{50}\right)$ can be used to estimate the ignition energy. The computational formulas of $H_{50}$ and ignition energy are as follows:

$$
\begin{aligned}
H_{50} & =\left[A+B\left[\frac{\sum i N_{i}}{N}-\frac{1}{2}\right]\right], \\
E_{i} \approx E_{p} & =\operatorname{mgH}_{50},
\end{aligned}
$$

where $A$ is the lowest height in the test, $B$ is the increment of height, $i$ is the order of the change of height beginning from $0, N_{i}$ is the number of reaction events under certain height which corresponds to $i, N$ is the number of reaction events in all tests, $E_{i}$ is the ignition energy of the specimen, $E_{p}$ is the potential energy of the drop mass, and $m$ is the mass of the drop hammer. The calculated results are listed in Table 3. As can be seen from Table 3, all six types of Al-PTFE specimens could react under drop hammer impact, and $H_{50}$ and ignition energy of specimen \#1 were highest, whereas those of specimen \# 6 were lowest. It can be concluded that the impact sensitivity of Al-PTFE material decreases and the ignition energy raises as the $\mathrm{Al}$ particle size rises. Furthermore, the change turned out to be comparatively evident for the $\mathrm{Al}$ particle size less than $10 \mu \mathrm{m}$, while the change tended to be progressively mild for the Al particle size more than $10 \mu \mathrm{m}$. In the meantime, the conclusion can be reached through comparing the unreacted phenomena of specimens \#4, \#5, and \#6 under quasistatic compression that the material takes on different mechanical properties and reaction characteristics under different strain rates, which demonstrates that the strain rate effect exists.

The high-speed video sequences of six types of Al-PTFE specimens are presented in Figure 8 under drop hammer impact, and the drop hammer fell from $H_{50}$ for each type of the specimen. The states of six types of specimens after impact are shown in Figure 9. As Figures 8 and 9 bespeak, a violent exothermic reaction occurred for specimens \#1, \#2, and \#3 under drop hammer impact, and the impact state indicates that the specimens reacted completely. Following the chemical equation between $\mathrm{Al}$ and PTFE, the black solid residuals remaining on the base of drop hammer tester can be proved to be $\mathrm{C}$. In contrast, the reaction phenomena of specimens \#4, \#5, and \#6 after impact were not obvious as a result of partial reaction, merely a faint flame occurred in specimen \#6, and then the reaction was terminated suddenly (Figure 8(f)). With the increase of the $\mathrm{Al}$ particle size, the 


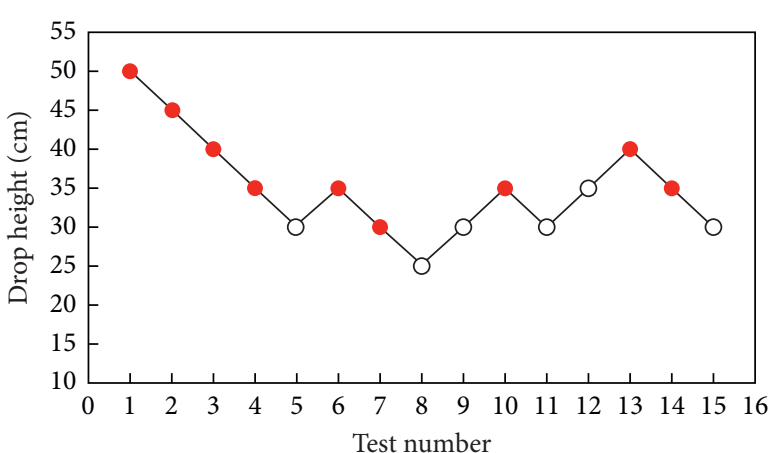

- Specimen \#1 reacted

O Specimen \#1 unreacted

(a)

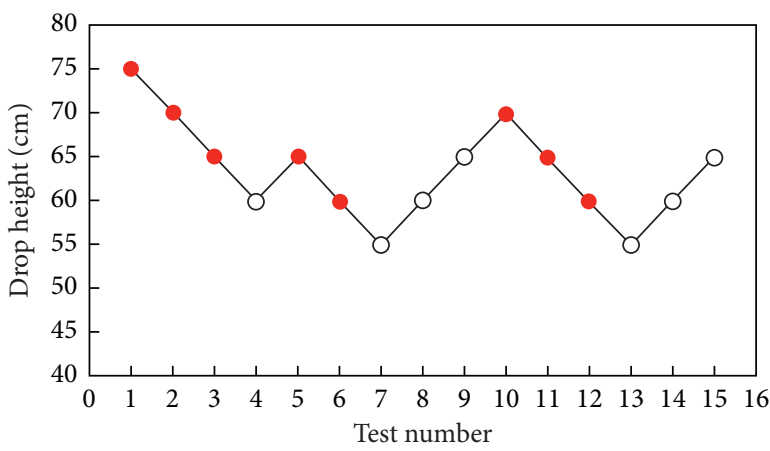

- Specimen \#3 reacted

○ Specimen \#3 unreacted

(c)

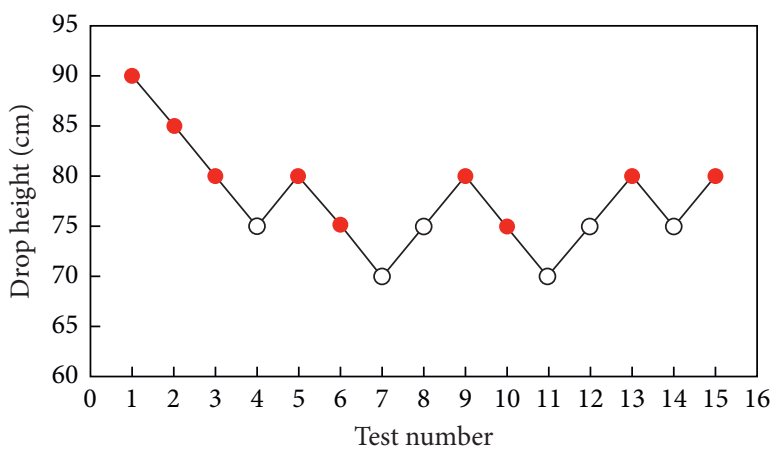

- Specimen \#5 reacted

O Specimen \#5 unreacted

(e)

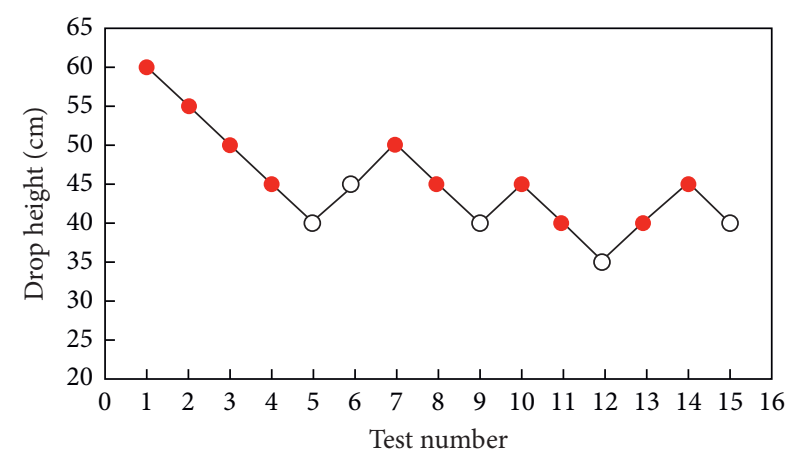

- Specimen \#2 reacted

O Specimen \#2 unreacted

(b)

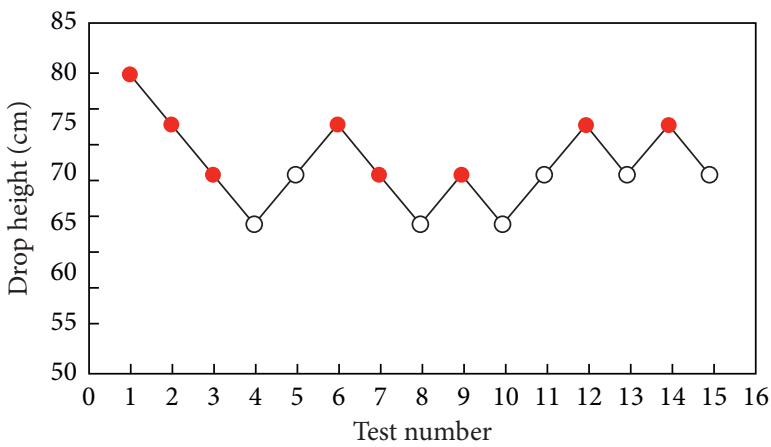

- Specimen \#4 reacted

O Specimen \#4 unreacted

(d)

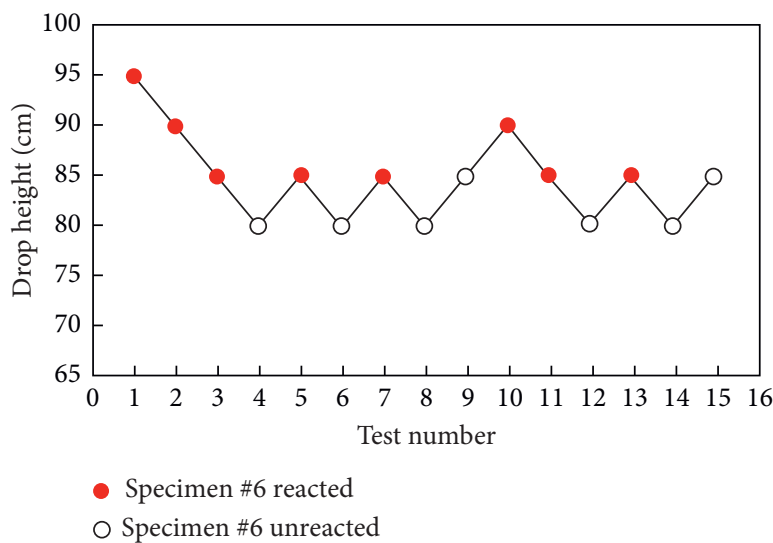

(f)

Figure 7: The drop weight test data points for specimens \#1-\#6.

TABLE 3: The characteristic drop height and ignition energy for specimens \#1-\#6.

\begin{tabular}{lcc}
\hline Number & $H_{50}(\mathrm{~cm})$ & $E_{i}(\mathrm{~J})$ \\
\hline 1 & 31.07 & 30.45 \\
2 & 44.50 & 43.61 \\
3 & 63.75 & 62.48 \\
4 & 71.25 & 69.83 \\
5 & 78.06 & 76.50 \\
6 & 85.00 & 83.30 \\
\hline
\end{tabular}

component of specimens participating in the reaction decreased accordingly, which resulted in the reaction intensity showing a downward trend. It is found through observing the morphology of the impacted specimens that the initial reaction of the specimens occurred in the circumferential open crack, which was consistent with the reaction phenomena manifested in the quasistatic compression test.

As the analysis of experimental results indicates, the impact sensitivity of the specimen was sensitive to the $\mathrm{Al}$ particle size, bespeaking that the reaction mechanism took 

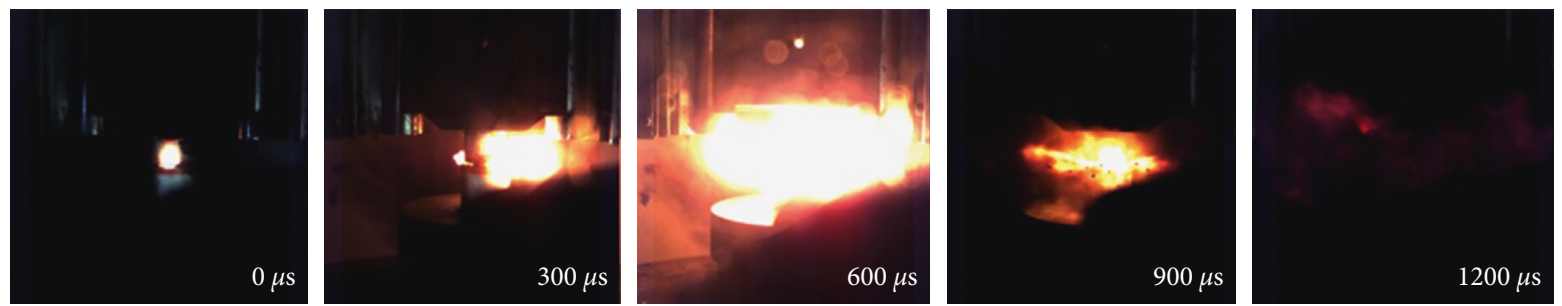

(a)
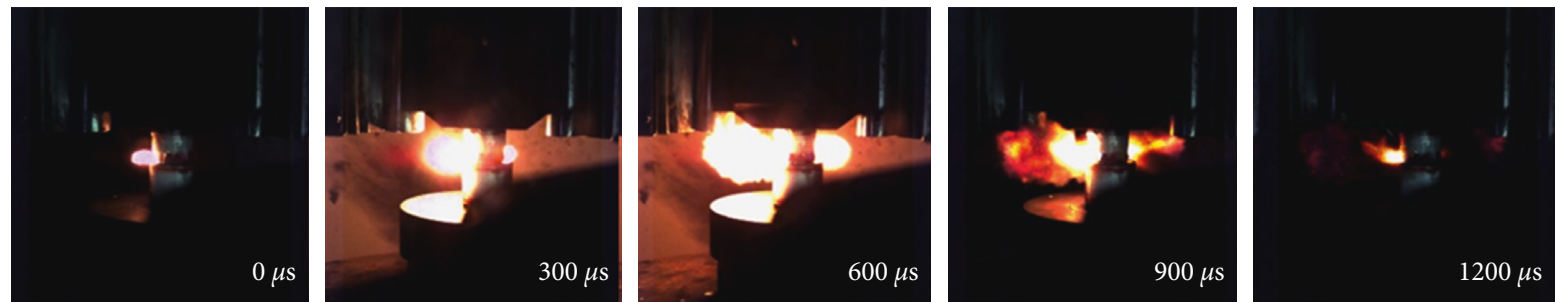

(b)
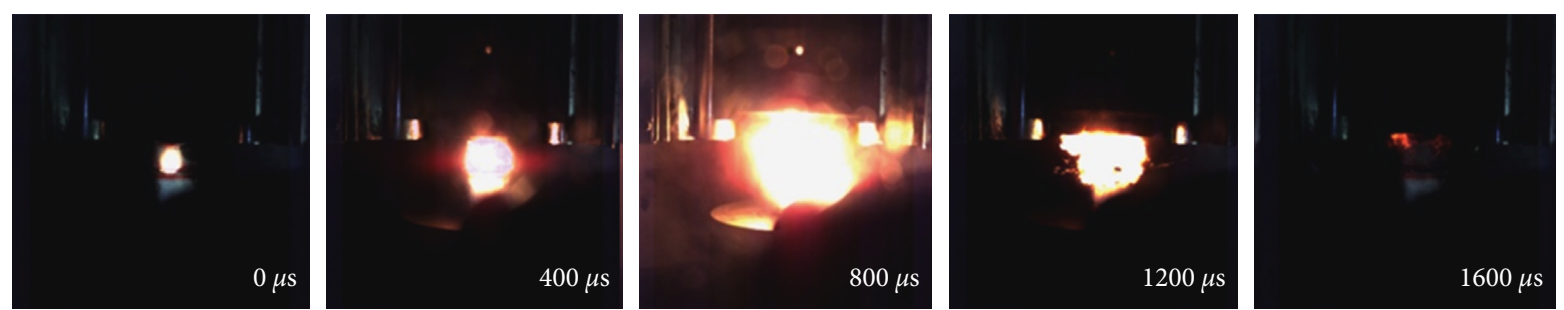

(c)
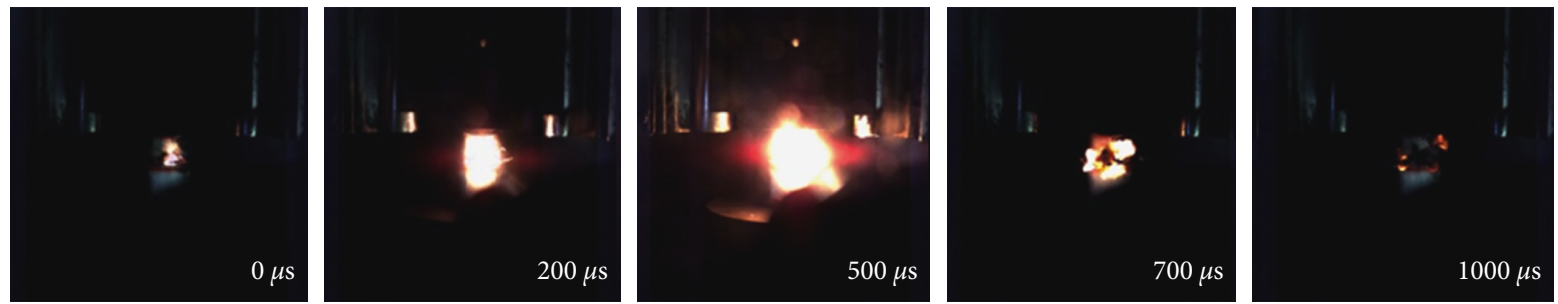

(d)
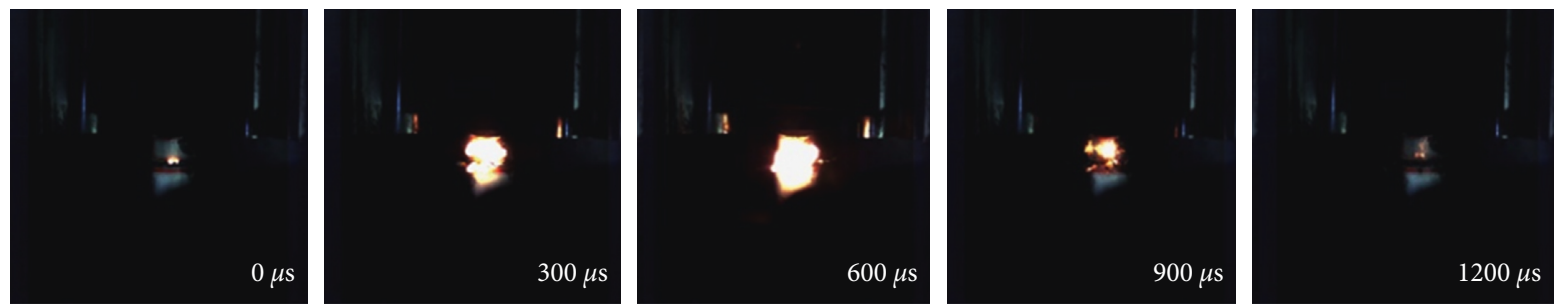

(e)
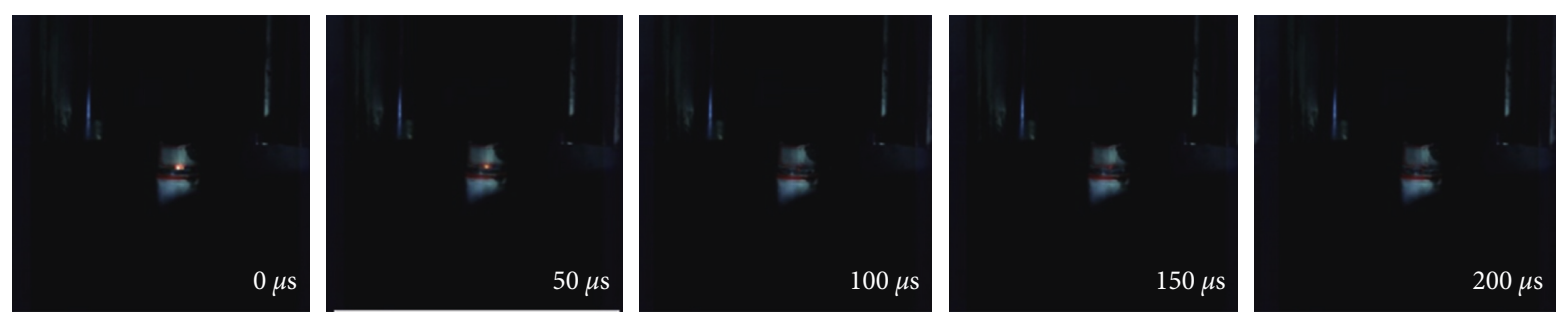

(f)

Figure 8: The reaction process of specimens \#1-\#6 under drop hammer impact. (a) Specimen \#1. (b) Specimen \#2. (c) Specimen \#3. (d) Specimen \#4. (e) Specimen \#5. (f) Specimen \#6. 

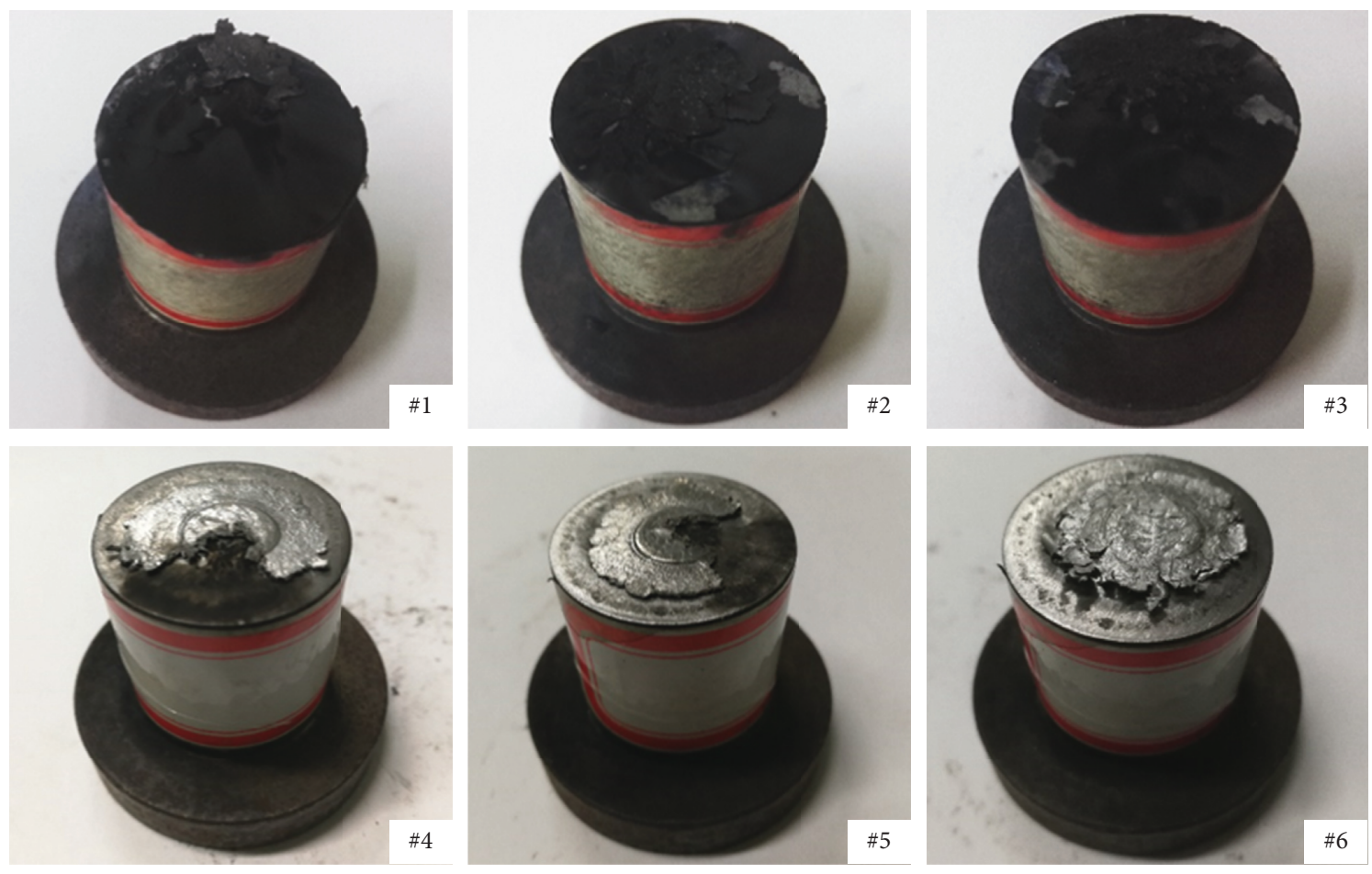

FIgURE 9: The states of specimens \#1-\#6 after drop hammer impact.

on obvious thermal diffusion reaction characteristics; that is, the oxidant and reductant propagate from the reaction interface to the periphery through the diffusion effect $[23,24]$. The specific surface area of $\mathrm{Al}$ particles decreased with the increase of the particle size, leading to the decline of diffusion distance between particles and the enlargement of friction area, which promoted the reaction activity of the material. Besides, when the $\mathrm{Al}$ particle size was in the level of micron, $H_{50}$ of the specimens changed linearly with the $\mathrm{Al}$ particle size; however, when the Al particle size was in the level of nano, it deviated from the trend obviously. The phenomenon was also arising from the acceleration of PIR reaction to the Al-PTFE reaction, and the excitation energy required for the reaction was reduced.

\section{Conclusions}

In this study, six types of Al-PTFE specimens with different Al particle sizes were prepared, and their mechanical properties and reaction characteristics under quasistatic compression and dynamic impact were investigated. The main conclusions are as follows:

(1) The stress-strain data under quasistatic compression show that the strength of the Al-PTFE specimen decreased with the increase of the Al particle size; the yield strength decreased from 22.7 MPa to $13.6 \mathrm{MPa}$; and the hardening modulus decreased from $33.3 \mathrm{MPa}$ to $25 \mathrm{MPa}$. And the toughness rose firstly and subsequently decreased, peaked as $116.42 \mathrm{MJ} / \mathrm{m}^{3}$ at $6 \sim 7 \mu \mathrm{m}$.

(2) In the quasistatic compression test, no reaction was occurred for specimens with the Al particle size of $12 \sim 14 \mu \mathrm{m}, 22 \sim 24 \mu \mathrm{m}$, and $32 \sim 34 \mu \mathrm{m}$, while an exothermic reaction was occurred for specimens with the Al particle size of $50 \mathrm{~nm}, 1 \sim 2 \mu \mathrm{m}$, and $6 \sim 7 \mu \mathrm{m}$. Arising from the function of surface effect and PIR, the reaction intensity and reaction speed showed a downward trend as the Al particle size rose.

(3) In the drop weight test, six types of specimens were overall reacted, and the characteristic drop height and ignition energy increased with the increase of the Al particle size, bespeaking that the material was more sensitive to reaction as the Al particle size rose. The change turned out to be comparatively evident for the $\mathrm{Al}$ particle size less than $10 \mu \mathrm{m}$, while the change tended to be progressively mild for the $\mathrm{Al}$ particle size more than $10 \mu \mathrm{m}$.

(4) In a lower strain rate range $\left(10^{-2} \cdot \mathrm{s}^{-1} \sim 10^{2} \cdot \mathrm{s}^{-1}\right)$, Al-PTFE specimens takes on different mechanical properties and reaction characteristics under different strain rates. The formation of circumferential open cracks is deemed as a prerequisite for Al-PTFE specimens to go through a reaction. With the increase of the $\mathrm{Al}$ particle size, the specimen is more difficult to form circumferential open crack and the reaction is more difficult to be triggered.

\section{Conflicts of Interest}

The authors declare that they have no conflicts of interest regarding the publication of this paper.

\section{Acknowledgments}

The financial support from the National Natural Science Foundation of China (General Program. Grant no. 51673213) is gratefully acknowledged. 


\section{References}

[1] D. B. Nielson, R. M. Truitt, and B. N. Ashcroft, "Reactive material enhanced projectiles and related methods," US Patent US7603951, 2009.

[2] W. Mock Jr. and W. H. Holt, "Impact initiation of rods of pressed polytetrafluoroethylene (PTFE) and aluminum powders," American Institute of Physics, vol. 845, pp. 10971100, 2006.

[3] E. M. Hunt, S. Malcolm, M. L. Pantoya, and F. Davis, "Impact ignition of nano and micron composite energetic materials," International Journal of Impact Engineering, vol. 36, no. 6, pp. 842-846, 2009.

[4] E. M. Hunt and M. L. Pantoya, "Impact sensitivity of intermetallic nanocomposites: a study on compositional and bulk density," Intermetallics, vol. 18, no. 8, pp. 1612-1616, 2010.

[5] S. Xu, S. Yang, and W. Zhang, "The mechanical behaviors of polytetrafluorethylene/Al/W energetic composites," Journal of Physics Condensed Matter, vol. 21, no. 28, p. 285401, 2009.

[6] J. Cai, S. M. Walley, R. J. A. Hunt, W. G. Proud, V. F. Nesterenko, and M. A. Meyers, "High-strain, high-strainrate flow and failure in PTFE/Al/W granular composites," Materials Science \& Engineering A, vol. 472, no. 1-2, pp. 308315, 2008.

[7] C. Ge, Y. Dong, and W. Maimaitituersun, "Microscale simulation on mechanical properties of Al/PTFE composite based on real microstructures," Materials, vol. 9, no. 12, p. 590, 2016.

[8] X. F. Zhang, J. Zhang, L. Qiao et al., "Experimental study of the compression properties of Al/W/PTFE granular composites under elevated strain rates," Materials Science \& Engineering A, vol. 581, no. 10, pp. 48-55, 2013.

[9] H. Wang, Y. Zheng, Q. Yu, and W. Yu, "Impact-induced initiation and energy release behavior of reactive materials," Journal of Applied Physics, vol. 110, no. 7, pp. 239-H03, 2011.

[10] L. Wang, J. Liu, S. Li, and X. Zhang, "Investigation on reaction energy, mechanical behavior and impact insensitivity of W-PTFE-Al composites with different W percentage," Materials \& Design, vol. 92, no. 5, pp. 397-404, 2016.

[11] L. Wang, J. Liu, S. Li, and X. Zhang, "Insensitive high-energy energetic structural material of tungsten-polytetrafluoroethylenealuminum composites," AIP Advances, vol. 5, no. 11, pp. 169$174,2015$.

[12] X. Zheng, A. D. Curtis, W. L. Shaw, and D. D. Dlott, "Shock initiation of nano-Al + Teflon: time-resolved emission studies," Journal of Physical Chemistry C, vol. 117, no. 9, pp. 4866-4875, 2013.

[13] B. Feng, Y. C. Li, S. Z. Wu, H.-X. Wang, Z.-M. Tao, and $\mathrm{X}$. Fang, "A crack-induced initiation mechanism of Al-PTFE under quasi-static compression and the investigation of influencing factors," Materials \& Design, vol. 108, pp. 411-417, 2016.

[14] B. Feng, X. Fang, Y. C. Li, S.-Z. Wu, Y.-M. Mao, and H.-X. Wang, "Reactions of Al-PTFE under impact and quasistatic compression," Advances in Materials Science \& Engineering, vol. 2015, Article ID 582320, 6 pages, 2015.

[15] C. Ge, W. Maimaitituersun, Y. Dong, and C. Tian, "A study on the mechanical properties and impact-induced initiation characteristics of brittle $\mathrm{PTFE} / \mathrm{Al} / \mathrm{W}$ reactive materials," Materials, vol. 10, no. 5, p. 452, 2017.

[16] H. X. Wang, Y. C. Li, B. Feng, J.-Y. Huang, S. Zhang, and $\mathrm{X}$. Fang, "Compressive properties of PTFE/Al/Ni composite under uniaxial loading," Journal of Materials Engineering \& Performance, vol. 26, no. 5, pp. 2331-2336, 2017.
[17] E. B. Herbold, V. F. Nesterenko, D. J. Benson et al., "Particle size effect on strength, failure, and shock behavior in polytetrafluoroethylene-Al-W granular composite materials," Journal of Applied Physics, vol. 104, no. 10, p. 103903, 2008.

[18] D. B. Nielson, R. L. Tanner, and G. K. Lund, "High strength reactive materials," US Patent US6593410, 2003.

[19] J. Cai, V. F. Nesterenko, K. S. Vecchio et al., "The influence of metallic particle size on the mechanical properties of polytetraflouroethylene-Al-W powder composites," Applied Physics Letters, vol. 92, no. 3, p. 1007, 2008.

[20] H. Altenbach, V. A. Eremeyev, and N. F. Morozov, "Mechanical properties of materials considering surface effects," Iutam Bookseries, vol. 31, pp. 105-115, 2013.

[21] D. T. Osborne and M. L. Pantoya, "Effect of Al particle size on the thermal degradation of $\mathrm{Al} /$ Teflon mixtures," Combustion Science \& Technology, vol. 179, no. 8, pp. 1467-1480, 2007.

[22] W. R. Blackstone, B. B. Baber, and P. M. Ku, "New test techniques for evaluating the compatibility of materials with liquid oxygen under impact," Tribology Transactions, vol. 11, no. 3, pp. 216-227, 1968.

[23] S. Chowdhury, K. Sullivan, N. Piekiel, L. Zhou, and M. R. Zachariah, "Diffusive versus explosive reaction at the nanoscale," Journal of Physical Chemistry C, vol. 114, no. 20, pp. 9191-9195, 2010.

[24] A. Rai, K. Park, L. Zhou, and M. R. Zachariah, "Understanding the mechanism of aluminium nanoparticle oxidation," Combustion Theory \& Modelling, vol. 10, no. 5, pp. 843-859, 2006. 


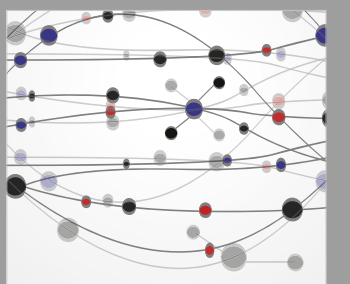

The Scientific World Journal
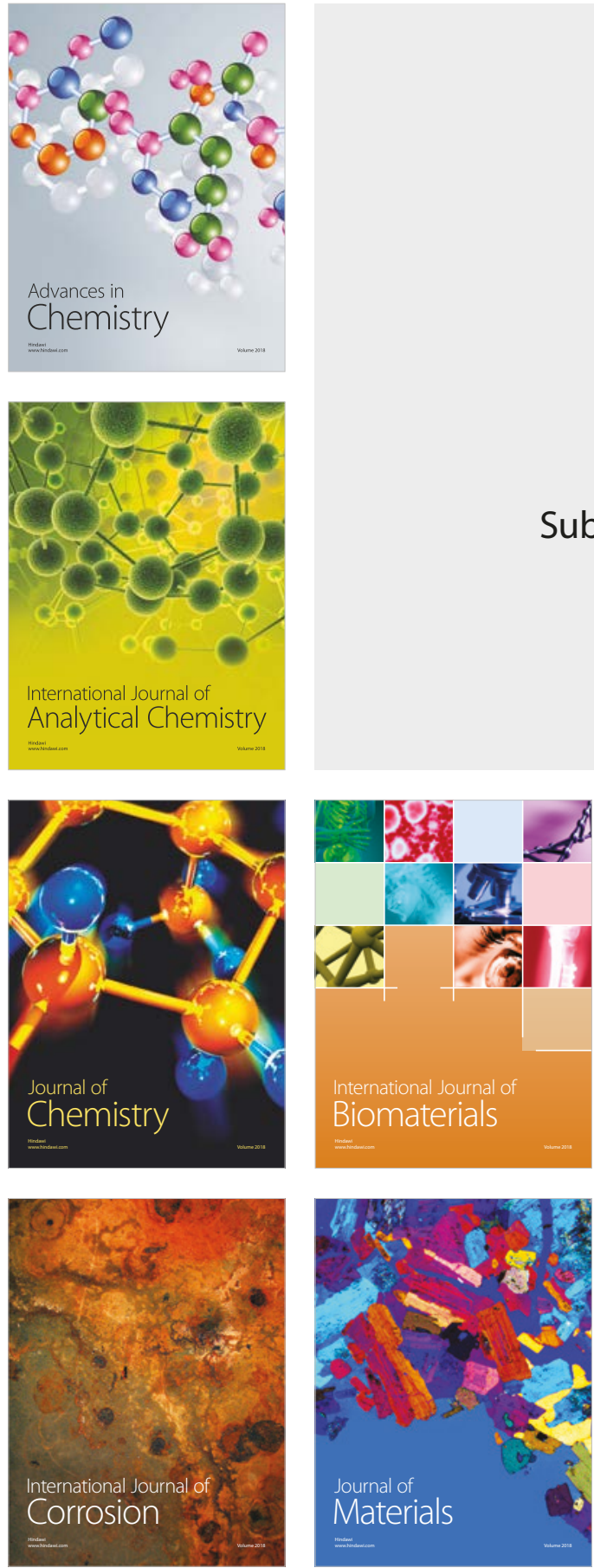

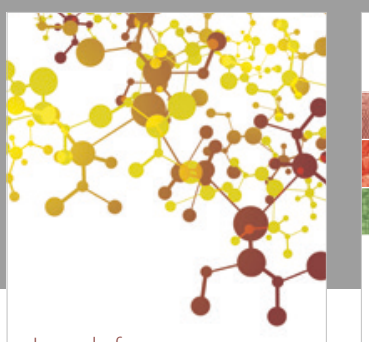

Journal of

Applied Chemistry
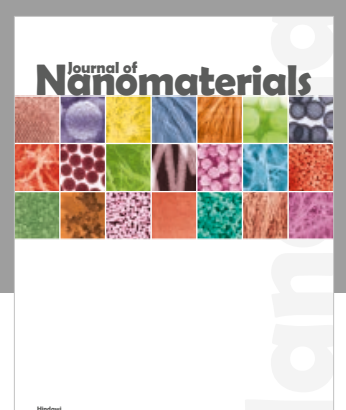

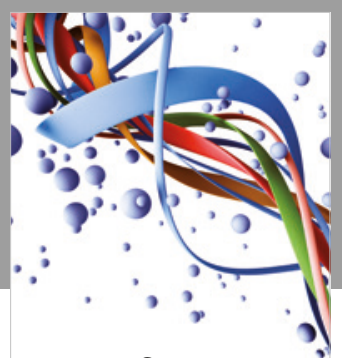

Scientifica

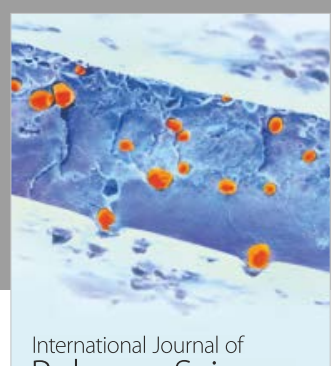

Polymer Science

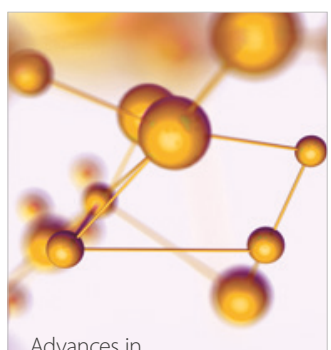

Physical Chemistry
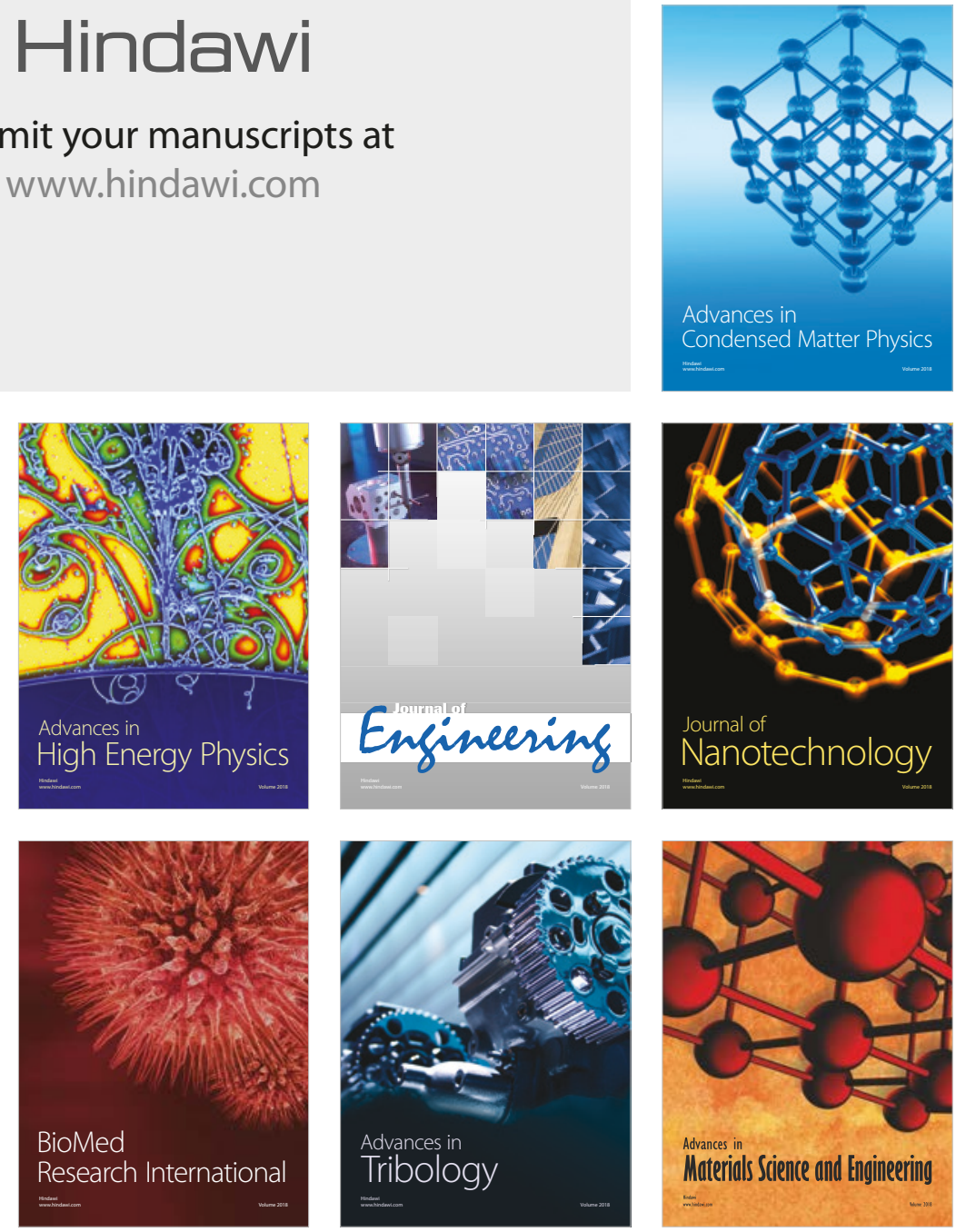